\title{
Enhanced In Vitro Cascade Catalysis of Glycerol into Pyruvate and Acetoin by Integration with Dihydroxy Acid Dehydratase from Paralcaligenes ureilyticus
}

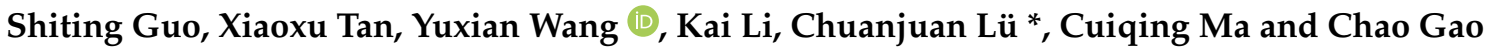

check for updates

Citation: Guo, S.; Tan, X.; Wang, Y.; Li, K.; Lü, C.; Ma, C.; Gao, C.

Enhanced In Vitro Cascade Catalysis of Glycerol into Pyruvate and Acetoin by Integration with Dihydroxy Acid Dehydratase from Paralcaligenes ureilyticus. Catalysts 2021, 11, 1282. https: / / doi.org/10.3390/ catal11111282

Academic Editors: Nicholas Harmer and Jennifer Littlechild

Received: 23 September 2021

Accepted: 18 October 2021

Published: 23 October 2021

Publisher's Note: MDPI stays neutral with regard to jurisdictional claims in published maps and institutional affiliations.

Copyright: (c) 2021 by the authors. Licensee MDPI, Basel, Switzerland. This article is an open access article distributed under the terms and conditions of the Creative Commons Attribution (CC BY) license (https:// creativecommons.org/licenses/by/ $4.0 /)$.
State Key Laboratory of Microbial Technology, Shandong University, Qingdao 266237, China; guoshiting66@mail.sdu.edu.cn (S.G.); tanxiaoxu@mail.sdu.edu.cn (X.T.); 201812522@mail.sdu.edu.cn (Y.W.); likai03721@sdu.edu.cn (K.L.); macq@sdu.edu.cn (C.M.); jieerbu@sdu.edu.cn (C.G.)

* Correspondence: chuanjuanlv@mail.sdu.edu.cn; Tel.: +86-532-58631561

Abstract: Recently, an in vitro enzymatic cascade was constructed to transform glycerol into the high-value platform chemical pyruvate. However, the low activity of dihydroxy acid dehydratase from Sulfolobus solfataricus (SsDHAD) limited the efficiency. In this study, the enzymatic reduction of pyruvate catalyzed by D-lactate dehydrogenase from Pseudomonas aeruginosa PAO1 was used to assay the activities of dihydroxy acid dehydratases. Dihydroxy acid dehydratase from Paralcaligenes ureilyticus (PuDHT) was identified as the most efficient candidate for glycerate dehydration. After the optimization of the catalytic temperature for the enzymatic cascade, comprising alditol oxidase from Streptomyces coelicolor A3, PuDHT, and catalase from Aspergillus niger, $20.50 \pm 0.27 \mathrm{mM}$ of glycerol was consumed in $4 \mathrm{~h}$ to produce $18.95 \pm 0.97 \mathrm{mM}$ of pyruvate with a productivity 12.15 -fold higher than the previous report using SsDHAD. The enzymatic cascade was further coupled with the pyruvate decarboxylase from Zymomonas mobile for the production of another platform compound, acetoin. Acetoin at a concentration of $8.52 \pm 0.12 \mathrm{mM}$ was produced from $21.62 \pm 0.19 \mathrm{mM}$ of glycerol with a productivity of $1.42 \pm 0.02 \mathrm{mM} \mathrm{h}^{-1}$.

Keywords: glycerol; pyruvate; acetoin; in vitro enzymatic cascade; dihydroxy acid dehydratase

\section{Introduction}

World production of glycerol, the main by-product of biodiesel and bioethanol generation, is now higher than the existing market demand for its industrial applications [1-3]. Glycerol can be transformed into different high value products by using chemical or biological routes [4-7]. Biological conversion is generally considered to be the preferred method of glycerol utilization due to its advantages of high selectivity, modest reaction condition, and low pollution risk [8,9]. Various valuable compounds such as 1,3-dihydroxyacetone [10,11], 1,3-propanediol [12], and succinate [13] have been produced by microbial fermentation using glycerol as a carbon source.

Pyruvate is an important platform compound which can be easily converted into a variety of valuable chemicals, such as acetoin [14], ethanol [15], and lactate [16]. Biosynthesis of pyruvate from glycerol by Yarrowia lipolytica through fermentation has also been extensively studied [17]. However, Y. lipolytica often synthesizes pyruvate and $\alpha$-ketoglutarate in approximately equal amounts, which leads to a decrease in theoretical yield and an increase in the difficulty of product separation [18-21]. In vitro enzymatic cascade, which leaves out the use of microbial cells and excludes undesired metabolism pathways, can also be used as a promising technique for the production of high-value products from glycerol. For example, alditol oxidase from Streptomyces coelicolor A3 (ScALDO, QKN69540.1, V125M/A244T/V133M/G399R), dihydroxy acid dehydratase from Sulfolobus solfataricus (SsDHAD, WP_063492879.1), and catalase from Aspergillus niger (CAT) were combined to construct an enzymatic cascade for converting glycerol into pyruvate [22]. The low 
efficiency of the dehydration of glycerate to pyruvate catalyzed by SsDHAD restricted the application of this enzymatic cascade. Pyruvate at a concentration of $9.3 \mathrm{mM}$ was generated from $10 \mathrm{mM}$ of glycerol after $24 \mathrm{~h}$ with a productivity of $0.39 \mathrm{mM} \mathrm{h}^{-1}$.

In the present study, we designed a convenient method for the determination of dihydroxy acid dehydratase activity toward glycerate. Dihydroxy acid dehydratase from Paralcaligenes ureilyticus (PuDHT, WP_132585145.1) was selected from three candidate dehydratases as the optimal one for glycerate conversion. After optimization of the reaction temperature, $18.95 \pm 0.97 \mathrm{mM}$ of pyruvate was generated from $20.50 \pm 0.27 \mathrm{mM}$ of glycerol with a productivity of $4.74 \pm 0.24 \mathrm{mM} \mathrm{h}^{-1}$ by ScALDO, PuDHT, and CAT. Then, acetoin, an important platform chemical, was also produced from glycerol by coupling with another enzyme, pyruvate decarboxylase, from Zymomonas mobile (ZmPDC, WP_014849477.1).

\section{Results}

\subsection{Design and Application of the Dehydratase Determination System}

The low activity of SsDHAD is the key factor limiting the efficiency of the entire in vitro enzymatic cascade based on glycerol. The activity of dihydroxy acid dehydratase might be detected by assaying the produced pyruvate from glycerate through high-performance liquid chromatography (HPLC) [23], amperometric biosensors [24,25], chemical derivatization [26] and enzymatic methods [27]. In this work, we selected the enzymatic reduction of pyruvate to D-lactate catalyzed by D-lactate dehydrogenase from Pseudomonas aeruginosa PAO1 (PaLdhA, NP_249618.1) to assay the activities of dihydroxy acid dehydratases [28,29]. Briefly, reduced nicotinamide adenine dinucleotide (NADH) is stoichiometrically oxidized to nicotinamide adenine dinucleotide $\left(\mathrm{NAD}^{+}\right)$during pyruvate reduction. The decrease in $\mathrm{NADH}$, which is proportional to pyruvate produced from glycerate, can be measured spectrophotometrically by using a spectrophotometer or a microplate spectrophotometer with 96-well plates (Figure 1a).

a

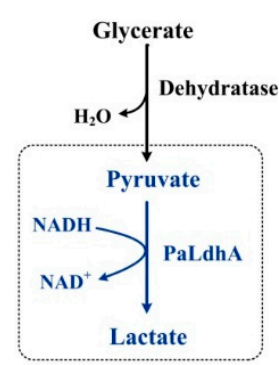

C

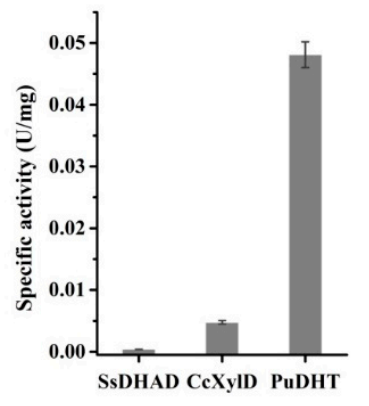

b
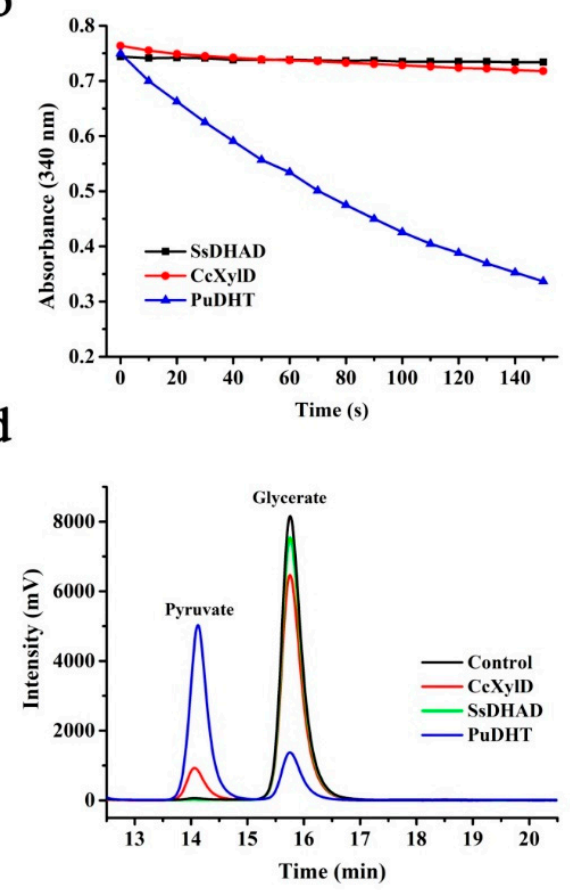

Figure 1. Selection of optimal dehydratase for glycerate conversion. (a) Scheme of the method for the determination of the activity of dehydratase toward glycerate. (b) Changes in absorbance at $340 \mathrm{~nm}$ caused by the coupled reaction catalyzed by D-lactate dehydrogenase from Pseudomonas aeruginosa PAO1 (PaLdhA) and three dehydratases including dihydroxy acid dehydratase from Sulfolobus solfataricus (SsDHAD), D-xylonate dehydratase from Caulobacter crescentus (CcXylD), and dihydroxy acid dehydratase from Paralcaligenes ureilyticus (PuDHT). (c) Specific activities of SsDHAD, CcXylD, and PuDHT toward glycerate. 
Values are the average \pm SD ( $n=3$ independent experiments). (d) High-performance liquid chromatography (HPLC) analysis of the glycerate dehydration catalyzed by SsDHAD, CcXylD, or PuDHT. The mixed reaction systems were incubated at $37^{\circ} \mathrm{C}$ and $150 \mathrm{rpm}$ for $3 \mathrm{~h}$ and then analyzed by HPLC. Black line, the reaction mixture with no dehydratase; red line, the reaction mixture with CcXylD; green line, the reaction mixture with SsDHAD; blue line, the reaction mixture with PuDHT.

Next, we applied the activity determination system to select the optimal dehydratase from three candidates including D-xylonate dehydratase from Caulobacter crescentus (CcXylD, Q9A9Z2.1) [30], SsDHAD, and PuDHT [31], a newly identified dehydratase with a high activity toward glycerate. As shown in Figure 1b,c, PuDHT showed the most satisfactory catalytic ability toward glycerate dehydration as expected (about 10 times that of CcXylD and 123 times that of SsDHAD). In addition, we further verified the dehydration activity of these three dehydratases by catalysis with glycerate as the substrate. As shown in Figure 1d, PuDHT catalyzed more glycerate into pyruvate than others in $3 \mathrm{~h}$, while only a little glycerate was catalyzed by SsDHAD to form an almost undetectable pyruvate. Thus, PuDHT was selected as the optimal dehydratase for successive experiments.

\subsection{Selection of the Suitable Reaction Temperature}

The optimum temperature and thermo-stability of enzymes in the in vitro enzymatic cascade are generally different from each other. Choosing a suitable catalytic temperature is required for the optimal performance of the multi-enzyme cascade catalytic system. Thus, the effects of temperature on the activities and stabilities of ScALDO and PuDHT were assessed at different temperatures as shown in Figure 2. The results indicate that ScALDO and PuDHT are affected differently by heat. ScALDO showed the highest activity at $42{ }^{\circ} \mathrm{C}$ while PuDHT showed the highest activity at $55^{\circ} \mathrm{C}$ (Figure 2a,b). ScALDO exhibited good thermo-stability at temperatures below $50^{\circ} \mathrm{C}$ (Figure 2c) while PuDHT exhibited good thermo-stability at temperatures below $45^{\circ} \mathrm{C}$ (Figure 2d). Thus, we chose $42{ }^{\circ} \mathrm{C}$ as the reaction temperature of the in vitro enzymatic cascade.

a

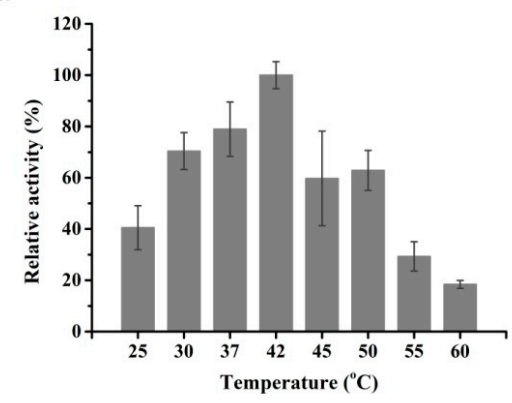

C

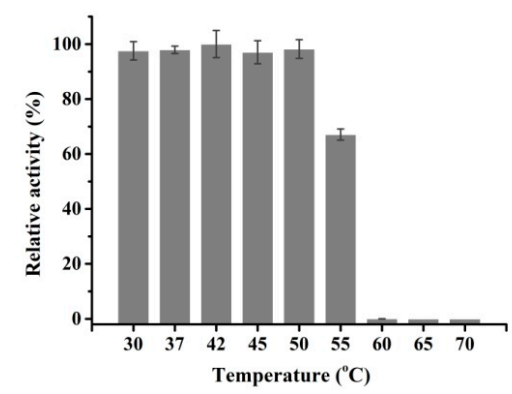

b

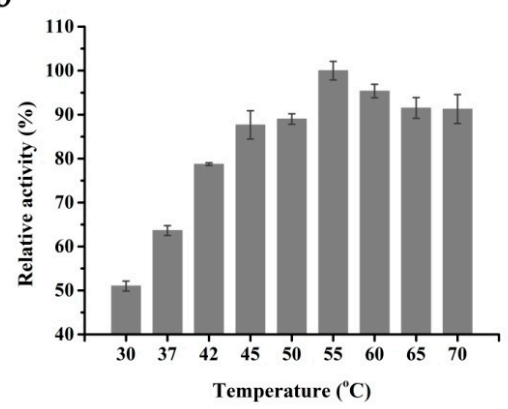

d

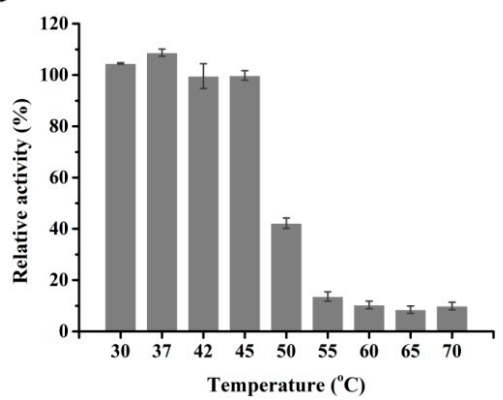

Figure 2. Effects of temperature on the activities and stabilities of alditol oxidase from Streptomyces coelicolor A3 (ScALDO) and PuDHT. (a) The effect of temperature on the activity of ScALDO toward glycerate. (b) The effect of temperature on the activity of PuDHT toward glycerate. (c) The stability of ScALDO at different temperatures. (d) The stability of PuDHT at different temperatures. Results are the average $\pm S D$ ( $n=3$ independent experiments). 


\subsection{Production of Pyruvate from Glycerol by In Vitro Enzymatic Cascade with PuDHT}

Then, pyruvate production from glycerol was carried out at $42{ }^{\circ} \mathrm{C}$ by an in vitro enzymatic cascade comprising ScALDO, PuDHT, and CAT. The detailed reaction process of pyruvate production from glycerol is described as shown in Figure 3a. Firstly, glycerol was oxidized to glycerate via a ScALDO-catalyzed two-step reaction accompanied by the consumption of oxygen and the generation of hydrogen peroxide. Then, glycerate was dehydrated to produce pyruvate by PuDHT. In addition, the glycerol oxidization step was coupled with CAT to decompose the undesirable byproduct hydrogen peroxide into oxygen and water [32,33]. Finally, one glycerol molecule can be converted into one pyruvate molecule with a high theoretical yield by the in vitro enzymatic cascade. Importantly, the reaction system did not require the addition of expensive cofactors such as $\mathrm{NAD}^{+}$which may enhance the economic feasibility of the in vitro enzymatic cascade.

a

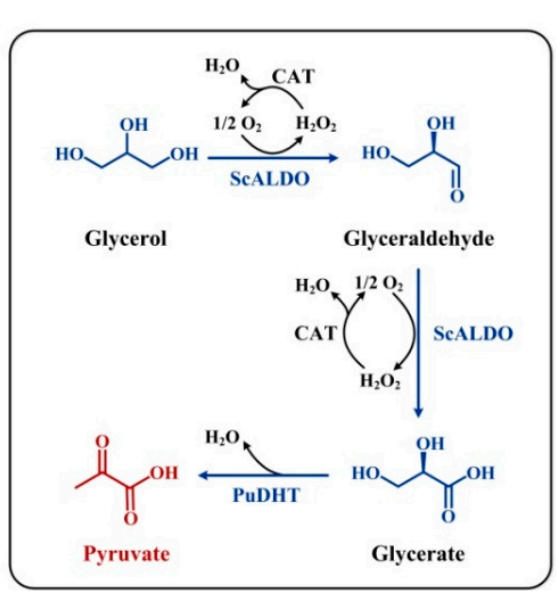

b

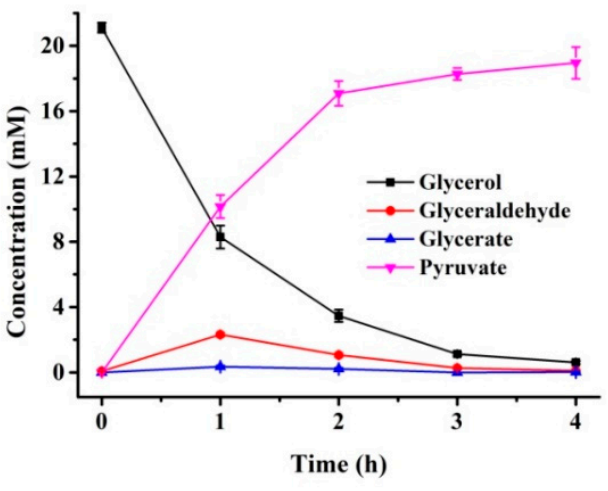

Figure 3. Production of pyruvate from glycerol by the multi-enzyme cascade catalysis. (a) Scheme of the production of pyruvate from glycerol catalyzed by ScALDO, PuDHT, and catalase from Aspergillus niger (CAT). (b) Time courses of the production of pyruvate from glycerol. The reaction mixture containing $20 \mathrm{mM}$ of glycerol, $1000 \mathrm{U} \mathrm{mL}^{-1}$ of CAT, $5 \mathrm{mM}$ of $\mathrm{MgCl}_{2}, 1 \mathrm{mg} \mathrm{mL}^{-1}$ of ScALDO, $10 \mathrm{mg}$ $\mathrm{mL}^{-1}$ of PuDHT, and $250 \mathrm{mM}$ of 4-(2-hydroxyethyl)-1-piperazineethanesulfonic acid (HEPES)-NaOH (pH 8.0) was incubated at $42{ }^{\circ} \mathrm{C}$ and $150 \mathrm{rpm}$ for $4 \mathrm{~h}$. Results are the average $\pm \mathrm{SD}$ ( $\mathrm{n}=3$ independent experiments).

As shown in Figure 3b, $20.50 \pm 0.27 \mathrm{mM}$ of glycerol was consumed in $4 \mathrm{~h}$ and $18.95 \pm 0.97 \mathrm{mM}$ of pyruvate was generated by using the in vitro enzymatic cascade. The yield of pyruvate reached $92.54 \pm 0.06 \%$ of the theoretical value. The productivity of pyruvate $\left(4.74 \pm 0.24 \mathrm{mM} \mathrm{h}^{-1}\right)$ was 12.15 -fold higher than that of the enzymatic cascade using SsDHAD without the optimized reaction temperature $\left(0.39 \mathrm{mM} \mathrm{h}^{-1}\right)$.

\subsection{Production of Acetoin from Glycerol by In Vitro Enzymatic Cascade Coupled with ZmPDC}

Acetoin is an important bio-based platform chemical with wide applications in the food, cosmetics, agriculture, and chemical industries [34,35]. The well-characterized acetoin biosynthesis pathway involves two key enzymes. $\alpha$-Acetolactate synthase (ALS) catalyzes the condensation of two molecules of pyruvate to generate $\alpha$-acetolactate. Then, $\alpha$-acetolactate is converted by $\alpha$-acetolactate decarboxylase (ALDC) into acetoin (Figure 4a). In a previous study, ALS and ALDC from Bacillus licheniformis 10-1-A were coupled with ScALDO, SsDHAD, and CAT to catalyze glycerol into acetoin with pyruvate as the intermediate [22]. Acetoin at a concentration of $4.4 \mathrm{mM}$ was generated from $10.4 \mathrm{mM}$ of glycerol with a productivity of $0.18 \mathrm{mM} \mathrm{h}^{-1}$. ZmPDC has been reported to catalyze the decarboxylation of pyruvate to form acetaldehyde and further condense acetaldehyde to produce acetoin (Figure 4b) [36]. Only one enzyme of ZmPDC was required to complete the conversion of pyruvate into acetoin. 
a

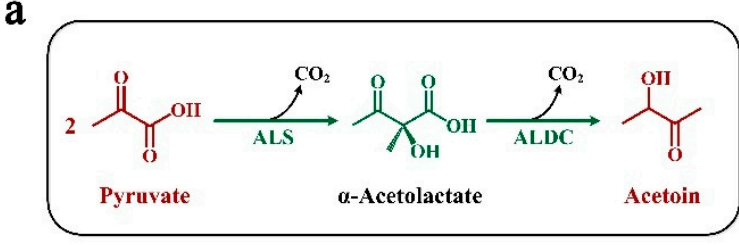

b

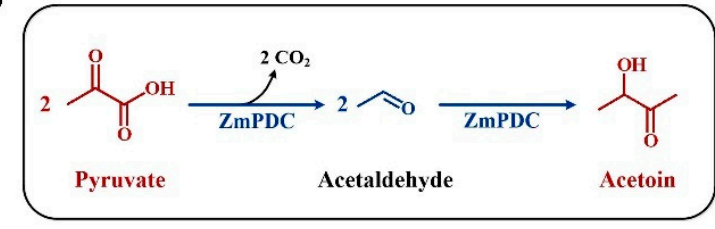

c

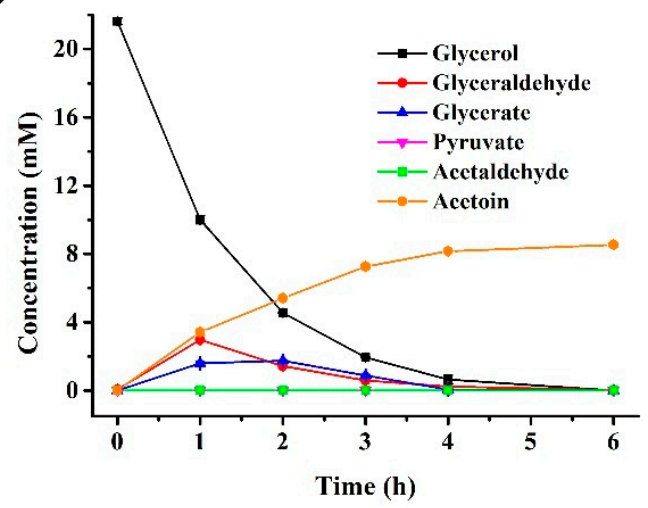

Figure 4. Production of acetoin from glycerol by the multi-enzyme cascade catalysis. (a) Scheme of the production of acetoin from pyruvate catalyzed by $\alpha$-acetolactate synthase (ALS) and $\alpha$-acetolactate decarboxylase (ALDC). (b) Scheme of the production of acetoin from pyruvate catalyzed by pyruvate decarboxylase from Zymomonas mobile (ZmPDC). (c) Time courses of the production of acetoin from glycerol. The reaction mixture containing $20 \mathrm{mM}$ of glycerol, $1000 \mathrm{U} \mathrm{mL}^{-1}$ of CAT, $5 \mathrm{mM}$ of $\mathrm{MgCl}_{2}, 1 \mathrm{mg} \mathrm{mL}^{-1}$ of ScALDO, $10 \mathrm{mg} \mathrm{mL}^{-1}$ of PuDHT, $2 \mathrm{mg} \mathrm{mL}^{-1}$ of ZmPDC, $0.2 \mathrm{mM}$ of thiamine pyrophosphate, and $250 \mathrm{mM}$ of HEPES-NaOH (pH 8.0) was incubated at $42{ }^{\circ} \mathrm{C}$ and $150 \mathrm{rpm}$ for $6 \mathrm{~h}$. Results are the average $\pm \mathrm{SD}(\mathrm{n}=3$ independent experiments).

Thus, an in vitro enzymatic cascade pathway with ScALDO, PuDHT, CAT, and ZmPDC was constructed for the production of acetoin from glycerol. As shown in Figure 4c, $21.62 \pm 0.19 \mathrm{mM}$ of glycerol was completely consumed in $6 \mathrm{~h}$ and $8.52 \pm 0.12 \mathrm{mM}$ of acetoin was produced without the accumulation of any intermediate (Figure 4c). The productivity of acetoin was $1.42 \pm 0.02 \mathrm{mM} \mathrm{h}^{-1}$, which was 7.89-fold higher than that of the enzymatic cascade using SsDHAD, ScALDO, ALS, and ALDC.

Pyruvate has both reactive carboxyl and ketonic groups and thus can be used as an important starting material in the chemical industry [37]. The large surplus of glycerol from the biofuel industry has caused a demand for the development of new processes to convert glycerol into valuable products. In this work, we used an enzymatic reaction cascade with glycerate as the key intermediate to produce pyruvate from glycerol.

Sutiono et al. recently screened PuDHT as an efficient biocatalyst to biotransform glycerate into pyruvate [31]. In this work, PuDHT was coupled with ScALDO and CAT to produce pyruvate from glycerol. A higher productivity of pyruvate was acquired than with our previously reported biocatalytic system with SsDHAD. However, this biocatalytic system is still far from an industrial application. Zhang et al. obtained an evolved ScALDO through three rounds of directed evolution and combined it with growth-coupled highthroughput selection [38]. The evolved ScALDO exhibited a higher affinity and catalytic efficiency toward glycerol. Introducing this evolved ScALDO into the in vitro multienzyme cascade may enhance the production of pyruvate from glycerol. Systematic optimization of the catalytic conditions such as the reaction $\mathrm{pH}$ and the concentrations of different enzymes through Box-Behnken design (BBD) may also improve the performance of the system.

\section{Materials and Methods}

\subsection{Materials}

Glycerol, glyceraldehyde, glycerate, pyruvate, isopropyl- $\beta$-D-thiogalactoside (IPTG), thiamine pyrophosphate (TPP), NADH, phenylmethanesulfonyl fluoride (PMSF), and CAT were purchased from Sigma-Aldrich (Saint Louis, MO, USA). Acetoin was obtained from Energy Chemical (Shanghai, China). $\mathrm{MgCl}_{2}$ was purchased from Sangon Biotech Co., Ltd. (Shanghai, China). Tryptone and yeast extract powder were purchased from Oxoid Limited (London, UK). FastPfu DNA polymerase was purchased from TransGen Biotech Co., Ltd. (Beijing, China). T4 DNA ligase and restriction endonuclease were purchased 
from Thermo Scientific (Waltham, MA, USA). All other chemicals were of analytical grade and commercially available.

\subsection{Strains and Plasmids}

The strains expressing ScALDO, SsDHAD, and ZmPDC used in this study were constructed in our previous work $[22,36]$. The gene encoding PuDHT was synthesized by General Biology (Anhui, China) after codon optimization and then ligated to pET28a $(+)$ via NdeI/Xhol restriction sites. The recombinant plasmid pET28a-PuDHT was then transferred into Escherichia coli BL21(DE3) for PuDHT expression. The gene encoding PaLdhA was amplified from the genome of P. aeruginosa PAO1 with the primers PaLdhA-F/PaLdhA$\mathrm{R}$ (Supplementary Table S1) and ligated to pETDuet-1 via BamHI/HindIII restriction sites to construct plasmid pETDuet-PaLdhA. pETDuet-PaLdhA was then transferred into $E$. coli BL21(DE3) to obtain the expression strain of PaLdhA. The pET28a-CcXylD constructed in our previous work was transferred into E. coli BL21(DE3) to construct the expression strain of CcXylD [39].

\subsection{Expression and Purification of Enzymes}

ScALDO, SsDHAD, and ZmPDC were purified as described previously [22,36]. The expression strain of PuDHT, CcXylD, or PaLdhA was cultured in Luria-Bertani (LB) medium with appropriate antibiotics at $37^{\circ} \mathrm{C}, 180 \mathrm{rpm}$ until the $\mathrm{OD}_{600}$ reached 0.4 to 0.6. After being induced overnight with $1 \mathrm{mM}$ of IPTG at $16^{\circ} \mathrm{C}$ and $160 \mathrm{rpm}$, cells were harvested by centrifugation at $6000 \times g$ for $10 \mathrm{~min}$, washed twice with phosphate buffer saline, and then resuspended in a binding buffer $(20 \mathrm{mM}$ of sodium phosphate, $20 \mathrm{mM}$ of imidazole, and $20 \mathrm{mM}$ of sodium chloride, $\mathrm{pH} 7.4$ ) containing $0.1 \mathrm{mM}$ of PMSF. The resuspended cells were lysed by a high-pressure homogenizer (ATS NANO TECHNOLOGY, Suzhou, China), and then the cell lysate was centrifuged at $12,000 \times g$ for $30 \mathrm{~min}$ at $4{ }^{\circ} \mathrm{C}$. The supernatant was filtered using a $0.22 \mu \mathrm{m}$ poly (ether sulfone) filter before being loaded into a $5 \mathrm{~mL}$ HisTrap HP column (GE Healthcare, Uppsala, Sweden). A gradient elution with elution buffer $(20 \mathrm{mM}$ of sodium phosphate, $20 \mathrm{mM}$ of imidazole, and $500 \mathrm{mM}$ of sodium chloride, $\mathrm{pH}$ 7.4) was performed to obtain the target protein. The purified protein was desalted into $250 \mathrm{mM}$ of 4-(2-hydroxyethyl)-1-piperazineethanesulfonic acid (HEPES)-NaOH buffer (pH 8.0) using a $5 \mathrm{~mL}$ HiTrap Desalting column (GE Healthcare, Uppsala, Sweden). Sodium dodecyl sulfate-polyacrylamide gel electrophoresis (SDS-PAGE) was used to analyze the size and purity of the target proteins.

\subsection{Dihydroxy Acid Dehydratase Activity Analysis}

The activity assays of dehydratases were performed using a microplate reader SpectraMax Plus 384 (Molecular Devices, San Jose, CA, USA) at $37^{\circ} \mathrm{C}$. The $200 \mu \mathrm{L}$ reaction solution contained $10 \mathrm{mM}$ of glycerate, $0.2 \mathrm{mM}$ of NADH, $1 \mathrm{mM}$ of $\mathrm{MgCl}_{2}, 5.5 \mu \mathrm{g} \mathrm{mL}^{-1}$ of PaLdhA, an appropriate amount of dehydratase (PuDHT $1 \mathrm{mg} \mathrm{mL}^{-1}$, SsDHAD $3 \mathrm{mg} \mathrm{mL}^{-1}$, or CcXylD $1 \mathrm{mg} \mathrm{mL}^{-1}$ ), and $100 \mathrm{mM}$ of HEPES-NaOH buffer (pH 7.0). The dehydratase was removed from the reaction mixture as a control. NADH consumption was measured at $340 \mathrm{~nm}$ to reflect the production of pyruvate. One unit of dehydratase activity was defined as the amount of protein needed to catalyze the consumption of $1 \mu \mathrm{mol}$ of NADH per minute.

\subsection{Identification of the Effects of Temperature on Activities and Stabilities of ScALDO and $\mathrm{PuDHT}$}

The activities of ScALDO at different temperatures were assayed in a reaction mixture containing $50 \mathrm{mM}$ of glycerol, $1000 \mathrm{U} \mathrm{mL}^{-1}$ of CAT, $1 \mathrm{mg} \mathrm{mL}^{-1}$ of ScALDO, and $250 \mathrm{mM}$ of HEPES-NaOH buffer ( $\mathrm{pH}$ 8.0). After incubation at $150 \mathrm{rpm}$ for $1 \mathrm{~h}$ at the corresponding temperature, the concentration of glycerate was assayed by HPLC. The highest activity of ScALDO at different temperatures was set at $100 \%$. The effects of temperature on the stability of ScALDO were studied by placing purified ScALDO at different temperatures for $1 \mathrm{~h}$, and then the residual enzyme activity was assayed at $37^{\circ} \mathrm{C}$ and $900 \mathrm{rpm}$ in a 
reaction mixture containing $20 \mathrm{mM}$ of glycerol, $0.27 \mathrm{mg} \mathrm{mL}^{-1}$ of ScALDO, and $100 \mathrm{mM}$ of HEPES-NaOH buffer ( $\mathrm{pH}$ 7.0) using an Oxytherm Clark-type oxygen electrode (Hansatech, Pentney, UK). The activity of the untreated ScALDO was determined at the same condition and set at $100 \%$. The effects of temperature on activity and stability of PuDHT were assayed through a similar method.

\subsection{Production Pyruvate and Acetoin from Glycerol}

The production of pyruvate from glycerol was performed in a reaction mixture containing $20 \mathrm{mM}$ of glycerol, $1000 \mathrm{U} \mathrm{mL}^{-1}$ of CAT, $5 \mathrm{mM}$ of $\mathrm{MgCl}_{2}, 1 \mathrm{mg} \mathrm{mL}^{-1}$ of ScALDO, $10 \mathrm{mg} \mathrm{mL}^{-1}$ of PuDHT, and $250 \mathrm{mM}$ of HEPES-NaOH buffer (pH 8.0) at $42{ }^{\circ} \mathrm{C}$ and $150 \mathrm{rpm}$. The production of acetoin from glycerol was conducted under the same conditions by the extra addition of $2 \mathrm{mg} \mathrm{mL}^{-1}$ of ZmPDC and $0.2 \mathrm{mM}$ of TPP. Samples were withdrawn every $1 \mathrm{~h}$ and the substrate consumption and product formation were assayed by HPLC.

\subsection{Analytical Methods}

The concentrations of glycerol, glyceraldehyde, glycerate, pyruvate, acetaldehyde, and acetoin were quantified by using an Agilent 1100 series HPLC (Hewlett-Packard, Palo Alto, Santa Clara, CA, USA) equipped with an Aminex HPX-87H column $(300 \times 7.8 \mathrm{~mm}$; Bio-Rad, Hercules, CA, USA) and a refractive index detector [22]. The mobile phase was $5 \mathrm{mM}$ of $\mathrm{H}_{2} \mathrm{SO}_{4}$ at a flow rate of $0.4 \mathrm{~mL} \mathrm{~min}^{-1}$ and $55^{\circ} \mathrm{C}$. The injection volume was $5 \mu \mathrm{L}$. The quantification of the compounds was conducted by converting the peak areas detected by HPLC to concentrations of target products using external calibration curves. The limit of quantification (LOQ) was established as the lowest point of the calibration curve.

\section{Conclusions}

In conclusion, PuDHT was selected as the optimal dehydratase for converting glycerate into pyruvate. An in vitro enzymatic cascade comprising ScALDO, PuDHT, and CAT was constructed for the production of pyruvate from glycerol. Pyruvate at a concentration of $18.95 \pm 0.97 \mathrm{mM}$ was produced from $20.50 \pm 0.27 \mathrm{mM}$ of glycerol with a yield of $0.92 \mathrm{~mol} \mathrm{~mol}^{-1}$ and a productivity of $4.73 \mathrm{mM} \mathrm{h}^{-1}$. In addition, $8.52 \pm 0.12 \mathrm{mM}$ of acetoin was produced from $21.62 \pm 0.19 \mathrm{mM}$ of glycerol with a yield of $0.79 \pm 0.02 \mathrm{~mol} \mathrm{~mol}^{-1}$ and a productivity of $1.42 \pm 0.02 \mathrm{mM} \mathrm{h}^{-1}$ by combining the in vitro enzymatic cascade with ZmPDC. The application of the in vitro enzymatic cascade may be extended to other value-added chemicals by coupling it with various enzymes.

Supplementary Materials: The following are available online at https:/ / www.mdpi.com/article/ 10.3390/catal11111282/s1, Figure S1: SDS-PAGE results of the purification of ScALDO, SsDHAD, CcXylD, PuDHT, and ZmPDC. (a) ScALDO. (b) SsDHAD. (c) CcXylD. (d) PuDHT. (e) ZmPDC. Lane M, molecular mass marker; lane 1, crude extract of E. coli BL21(DE3); lane 2, crude extracts of $E$. coli BL21(DE3) harboring expression vectors of different proteins; lane 3, purified target proteins. Figure S2: SDS-PAGE result of the purification of PaLdhA. Lane M, molecular mass marker; lane 1, purified PaLdhA. Figure S3: Calibration curves for the concentrations assayed by HPLC. (a) Glycerol. (b) Glyceraldehyde. (c) Glycerate. (d) Pyruvate. (e) Acetoin. Table S1: Strains, plasmids, and primers used in this study.

Author Contributions: Conceptualization, methodology, formal analysis, investigation, data curation, S.G. and C.L.; software, validation, X.T. and Y.W.; resources, S.G. and K.L.; writing-original draft preparation, S.G., X.T. and C.G.; writing—review and editing, supervision, project administration, C.L. and C.M.; funding acquisition, C.L., C.G. and C.M. All authors have read and agreed to the published version of the manuscript.

Funding: This research was funded by National Key R\&D Program of China, grant number 2019YFA0904900, 2019YFA0904800; Natural Science Foundation of Shandong Provincial, grant number ZR2018PC008, ZR2020MC005; and Tianjin Synthetic Biotechnology Innovation Capacity Improvement Project, grant number TSBICIP-KJGG-005. 
Data Availability Statement: All the data presented in this study are contained within the article or the supplementary material. Additional data related to this paper may be requested from the authors.

Acknowledgments: The authors thank Xiangmei Ren from Core Facilities for Life and Environmental Sciences (State Key Laboratory of Microbial Technology, Shandong University) for assistance in HPLC analysis.

Conflicts of Interest: The authors declare no conflict of interest. The funders had no role in the design of the study; in the collection, analyses, or interpretation of data; in the writing of the manuscript, or in the decision to publish the results.

\section{References}

1. Makris, D.P.; Lalas, S. Glycerol and glycerol-based deep eutectic mixtures as emerging green solvents for polyphenol extraction: The evidence so far. Molecules 2020, 25, 5842. [CrossRef]

2. Rahim, S.A.N.M.; Lee, C.S.; Abnisa, F.; Aroua, M.K.; Daud, W.A.W.; Cognet, P.; Pérès, Y. A review of recent developments on kinetics parameters for glycerol electrochemical conversion-A by-product of biodiesel. Sci. Total Environ. 2020, 705, 135137. [CrossRef]

3. Kumar, L.R.; Yellapu, S.K.; Tyagi, R.D.; Zhang, X. A review on variation in crude glycerol composition, bio-valorization of crude and purified glycerol as carbon source for lipid production. Bioresour. Technol. 2019, 293, 122155. [CrossRef]

4. Wang, Y.; Furukawa, S.; Song, S.; He, Q.; Asakura, H.; Yan, N. Catalytic production of alanine from waste glycerol. Angew. Chem. Int. Ed. Engl. 2020, 59, 2289-2293. [CrossRef]

5. Lee, S.; Kim, H.J.; Lim, E.J.; Kim, Y.; Noh, Y.; Huber, G.W.; Kim, W.B. Highly selective transformation of glycerol to dihydroxyacetone without using oxidants by a PtSb/C-catalyzed electrooxidation process. Green Chem. 2016, 18, 2877-2887. [CrossRef]

6. Murakami, N.; Oba, M.; Iwamoto, M.; Tashiro, Y.; Noguchi, T.; Bonkohara, K.; Abdel-Rahman, M.A.; Zendo, T.; Shimoda, M.; Sakai, K.; et al. L-Lactic acid production from glycerol coupled with acetic acid metabolism by Enterococcus faecalis without carbon loss. J. Biosci. Bioeng. 2016, 121, 89-95. [CrossRef]

7. Kaur, J.; Sarma, A.K.; Jha, M.K.; Gera, P. Valorisation of crude glycerol to value-added products: Perspectives of process technology, economics and environmental issues. Biotechnol. Rep. (Amst.) 2020, 27, e00487. [CrossRef] [PubMed]

8. Khanna, S.; Goyal, A.; Moholkar, V.S. Microbial conversion of glycerol: Present status and future prospects. Crit. Rev. Biotechnol. 2012, 32, 235-262. [CrossRef]

9. Yazdani, S.S.; Gonzalez, R. Anaerobic fermentation of glycerol: A path to economic viability for the biofuels industry. Curr. Opin. Biotechnol. 2007, 18, 213-219. [CrossRef] [PubMed]

10. Hu, Z.C.; Zheng, Y.G.; Shen, Y.C. Use of glycerol for producing 1,3-dihydroxyacetone by Gluconobacter oxydans in an airlift bioreactor. Bioresour. Technol. 2011, 102, 7177-7182. [CrossRef]

11. Dikshit, P.K.; Moholkar, V.S. Optimization of 1,3-dihydroxyacetone production from crude glycerol by immobilized Gluconobacter oxydans MTCC 904. Bioresour. Technol. 2016, 216, 1058-1065. [CrossRef]

12. Przystałowska, H.; Lipiński, D.; Słomski, R. Biotechnological conversion of glycerol from biofuels to 1,3-propanediol using Escherichia coli. Acta. Biochim. Pol. 2015, 62, 23-34. [CrossRef]

13. Yu, Y.; Zhu, X.; Xu, H.; Zhang, X. Construction of an energy-conserving glycerol utilization pathways for improving anaerobic succinate production in Escherichia coli. Metab. Eng. 2019, 56, 181-189. [CrossRef]

14. Ge, Y.; Li, K.; Li, L.; Gao, C.; Zhang, L.; Ma, C.; Xu, P. Contracted but effective: Production of enantiopure 2, 3-butanediol by thermophilic and GRAS Bacillus licheniformis. Green Chem. 2016, 18, 4693-4703. [CrossRef]

15. Olson, D.G.; Sparling, R.; Lynd, L.R. Ethanol production by engineered thermophiles. Curr. Opin. Biotechnol. 2015, 33, 130-141. [CrossRef]

16. Akita, H.; Nakashima, N.; Hoshino, T. Production of D-lactate using a pyruvate-producing Escherichia coli strain. Biosci. Biotechnol. Biochem. 2017, 81, 1452-1455. [CrossRef]

17. Cybulski, K.; Tomaszewska-Hetman, L.; Rakicka, M.; Juszczyk, P.; Rywińska, A. Production of pyruvic acid from glycerol by Yarrowia lipolytica. Folia. Microbiol. (Praha) 2019, 64, 809-820. [CrossRef] [PubMed]

18. Kamzolova, S.V.; Morgunov, I.G. Biosynthesis of pyruvic acid from glycerol-containing substrates and its regulation in the yeast Yarrowia lipolytica. Bioresour. Technol. 2018, 266, 125-133. [CrossRef] [PubMed]

19. Otto, C.; Yovkova, V.; Aurich, A.; Mauersberger, S.; Barth, G. Variation of the by-product spectrum during $\alpha$-ketoglutaric acid production from raw glycerol by overexpression of fumarase and pyruvate carboxylase genes in Yarrowia lipolytica. Appl. Microbiol. Biotechnol. 2012, 95, 905-917. [CrossRef] [PubMed]

20. Guo, H.; Madzak, C.; Du, G.; Zhou, J.; Chen, J. Effects of pyruvate dehydrogenase subunits overexpression on the $\alpha$-ketoglutarate production in Yarrowia lipolytica WSH-Z06. Appl. Microbiol. Biotechnol. 2014, 98, 7003-7012. [CrossRef]

21. Zeng, W.; Zhang, H.; Xu, S.; Fang, F.; Zhou, J. Biosynthesis of keto acids by fed-batch culture of Yarrowia lipolytica WSH-Z06. Bioresour. Technol. 2017, 243, 1037-1043. [CrossRef]

22. Gao, C.; Li, Z.; Zhang, L.; Wang, C.; Li, K.; Ma, C.; Xu, P. An artificial enzymatic reaction cascade for a cell-free bio-system based on glycerol. Green Chem. 2015, 17, 804-807. [CrossRef] 
23. Carsten, J.M.; Schmidt, A.; Sieber, V. Characterization of recombinantly expressed dihydroxy-acid dehydratase from Sulfobus solfataricus-A key enzyme for the conversion of carbohydrates into chemicals. J. Biotechnol. 2015, 211, 31-41. [CrossRef]

24. Belluzo, M.S.; Ribone, M.É.; Lagier, C.M. Assembling amperometric biosensors for clinical diagnostics. Sensors 2008, 8, 1366-1399. [CrossRef]

25. Gilis, M.; Durliat, H.; Comtat, M. Amperometric biosensors for L-alanine and pyruvate assays in biological fluids. Anal. Chim. Acta. 1997, 355, 235-240. [CrossRef]

26. Yu, Z.; Huang, H.; Reim, A.; Charles, P.D.; Northage, A.; Jackson, D.; Parry, I.; Kessler, B.M. Optimizing 2D gas chromatography mass spectrometry for robust tissue, serum and urine metabolite profiling. Talanta 2017, 165, 685-691. [CrossRef] [PubMed]

27. Lu, J.; Grenache, D.G. Development of an automated enzymatic method to quantify pyruvate kinase in red blood cells. J. Appl. Lab. Med. 2020, 5, 54-61. [CrossRef] [PubMed]

28. Furukawa, N.; Miyanaga, A.; Togawa, M.; Nakajima, M.; Taguchi, H. Diverse allosteric and catalytic functions of tetrameric D-lactate dehydrogenases from three Gram-negative bacteria. AMB Express 2014, 4, 76. [CrossRef]

29. Furukawa, N.; Miyanaga, A.; Nakajima, M.; Taguchi, H. Structural basis of sequential allosteric transitions in tetrameric D-lactate dehydrogenases from three Gram-negative bacteria. Biochemistry 2018, 57, 5388-5406. [CrossRef]

30. Andberg, M.; Aro-Kärkkäinen, N.; Carlson, P.; Oja, M.; Bozonnet, S.; Toivari, M.; Hakulinen, N.; O’Donohue, M.; Penttilä, M.; Koivula, A. Characterization and mutagenesis of two novel iron-sulphur cluster pentonate dehydratases. Appl. Microbiol. Biotechnol. 2016, 100, 7549-7563. [CrossRef]

31. Sutiono, S.; Teshima, M.; Beer, B.; Schenk, G.; Sieber, V. Enabling the direct enzymatic dehydration of D-glycerate to pyruvate as the key step in synthetic enzyme cascades used in the cell-free production of fine chemicals. ACS Catal. 2020, 10, 3110-3118. [CrossRef]

32. Switala, J.; Loewen, P.C. Diversity of properties among catalases. Arch. Biochem. Biophys. 2002, 401, 145-154. [CrossRef]

33. Fiedurek, J.; Gromada, A. Production of catalase and glucose oxidase by Aspergillus niger using unconventional oxygenation of culture. J. Appl. Microbiol. 2000, 89, 85-89. [CrossRef]

34. Lü, C.; Ge, Y.; Cao, M.; Guo, X.; Liu, P.; Gao, C.; Xu, P.; Ma, C. Metabolic engineering of Bacillus licheniformis for production of acetoin. Front. Bioeng. Biotechnol. 2020, 8, 125. [CrossRef] [PubMed]

35. Xiao, Z.; Lu, J.R. Strategies for enhancing fermentative production of acetoin: A review. Biotechnol. Adv. 2014, 32, 492-503. [CrossRef]

36. Li, Z.; Zhang, M.; Jiang, T.; Sheng, B.; Ma, C.; Xu, P.; Gao, C. Enzymatic cascades for efficient biotransformation of racemic lactate derived from corn steep water. ACS Sustainable Chem. Eng. 2017, 5, 3456-3464. [CrossRef]

37. Zhu, Y.; Eiteman, M.A.; Altman, R.; Altman, E. High glycolytic flux improves pyruvate production by a metabolically engineered Escherichia coli strain. Appl. Environ. Microbiol. 2008, 74, 6649-6655. [CrossRef]

38. Zhang, C.; Chen, Q.; Fan, F.; Tang, J.; Zhan, T.; Wang, H.; Zhang, X. Directed evolution of alditol oxidase for the production of optically pure D-glycerate from glycerol in the engineered Escherichia coli. J. Ind. Microbiol. Biotechnol. 2021, 48, 7-8. [CrossRef] [PubMed]

39. Zhang, Y.; Liu, Y.; Zhu, J.; Xiao, D.; Xu, P.; Ma, C.; Gao, C.; Lü, C. Coculture of Gluconobacter oxydans and Escherichia coli for 3, 4-dihydroxybutyric acid production from xylose. ACS Sustainable Chem. Eng. 2021, 9, 10809-10817. [CrossRef] 